\title{
Estimation of Serum Magnesium in Bangladeshi Gestational Diabetic Mother
}

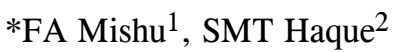

\begin{abstract}
Background: Gestational diabetes mellitus (GDM) is characterized by glucose intolerance during pregnancy.GDM is associated with an increased incidence of congenital abnormalities usually aggravated by maternal magnesium deficiency. Magnesium is one of the essential trace elements for normal embryogenesis and foetal growth and its deficiency increase mortality and morbidity rate of mothers, embryos and neonates.
\end{abstract}

Objective: To evaluate the association of serum magnesium with GDM in second and third trimester.

Materials \& Methods: This case control study was conducted in Mymensingh Medical College Hospital during the period from July 2013 to June 2014 to evaluate the association of magnesium with GDM in Bangladeshi women. A total number of 172 subjects were participated in this study; among them eighty six women diagnosed with GDM were selected as case (Group-I) and eighty six healthy pregnant women were control (Group-II). The case group again subdivided as Group Ia and Ib second and third trimester respectively. Control group also subdivided as Group IIa and IIb second and third trimester respectively. Student's unpaired t test was used to analyse the data between groups. For analytical purpose $95 \%$ confidence limit $(\mathrm{p}<0.05)$ was taken as level of significance.

Results: Serum Magnesium levels were significantly decreased in cases compared to control group. Highly significant difference $(\mathrm{p}<0.001)$ was found between Gr-Ia and Gr-IIa. The result was also highly significant $(\mathrm{p}<0.001)$ when compared between Gr-Ib and Gr-IIb .

Conclusion: Estimation of serum magnesium level should be incorporated in every GDM cases for prevention of complications.

Key Words: Diabetes mellitus, GDM, OGTT, Trace elements.

\section{Introduction}

Gestational diabetes mellitus is defined as carbohydrate intolerance resulting in hyperglycemia, with first onset or detection during pregnancy. ${ }^{1,2}$ Approximately 1-14\% of all pregnancies are complicated by GDM. ${ }^{3}$ The incidence of GDM in Bangladesh is $6.7 \%$ among all Bangladeshi pregnant mothers. ${ }^{4}$ Frequency of congenital malformation in infants of diabetic mothers is estimated to be 6$10 \% .^{5}$ Gestational diabetes is associated with excessive nutrient losses due to glycosuria. ${ }^{6}$ Different researchers demonstrated that micro and macro nutrients are essential for the development of fetus. ${ }^{7}$ Magnesium is fourth most abundant cation in human body, which is related to the carbohydrate and fat metabolism. ${ }^{8}$ Magnesium has established its role in obstetrics with its relationship to both foetal and maternal wellbeing. The low concentration of magnesium in serum exposes the subject to a risk of pregnancy complications. Magnesium has established its role in obstetrics with its relationship to both foetal and maternal wellbeing. Magnesium is one of the important minerals which is required

$1 * D r$. Farzana Akonjee Mishu, Assistant Professor and Senior Research Officer, Physiology and Molecular Biology, BIRDEM, Dhaka, Bangladesh

${ }^{2}$ Dr. Syed Md. Tanjilul Haque, Associate Professor, Department of Forensic Medicine, Anwer Khan Modern Medical College, Dhaka

*Corresponding Author

Date of submission: 12.02.2018, Date of acceptance: 22.03.2018

AKMMC J 2018; 9(2) : 110-113 
for cell multiplication in a growing foetus and is an essential element of life chemistry in keeping a balanced neuromuscular system. ${ }^{9}$ The low concentration of magnesium in serum exposes the subject to a risk of pregnancy complications hypertension, preeclampsia, IUGR (Intra uterine growth retardation), preterm labour, low birth weight baby and SIDS (sudden infant death syndrome). ${ }^{10}$ The reason for reduction of Magnesium concentration is not clear. An increase is the renal clearance during pregnancy may contribute to the reduction in serum Magnesium concentration, since the Kidney is the main regulator of the body magnesium concentration. ${ }^{11}$ Pregnant women tend to have low magnesium level than non pregnant because of increase demand for mother and growing foetus and increase renal excretion of magnesium $25 \%$ more than nonpregnant women due to increase GFR in second and third trimester. ${ }^{12}$ The magnesium deficiency in pregnant ladies will lead to life threatening complications for mother as well as their babies that can be prevented by timely detection and proper management of magnesium deficiency. Pregnant women generally have lower plasma magnesium levels compared to non pregnant women. Bardicef et al. (1995) found that women with GDM had lower levels of plasma magnesium. ${ }^{17}$

\section{Materials and Methods}

This case control study was carried out from July 2013 to June 2014 in the department of biochemistry. Total 172 subjects were selected by purposive sampling technique from the outpatient department of Obstetrics and Gynaecology and department of Endocrinology in Mymensingh Medical College Hospital. Clinically diagnosed GDM $(n=86)$ was in the case group and it was done on the basis of OGTT by WHO criteria 2013. Case group was subgrouped into $\mathrm{Gr}-\mathrm{Ia}(43)$ and $\mathrm{Gr}-\mathrm{Ib}$ (43) at second and third trimester respectively. The normoglycemic pregnant women at second and third trimester were taken as control group $(\mathrm{n}=86)$ and sub grouped as Gr-IIa $(n=43)$ and Gr-IIb $(n=43)$ respectively. All those pregnant women with the previous history of diabetes, hypertension, and other endocrine disorders were excluded from this study. This study protocol was approved by the institutional review committee. Data were collected through a preformed data collection sheet (questionnaire). The variables were included age, education, occupation, socioeconomic status, residential address, dietary habit, height, weight, family history of diabetes, previous pregnancy history, Previous history of gestational diabetes mellitus. Written informed consent was obtained from all the participants of the study groups prior to their enrolment into this study. Blood samples, from pregnant women, which was withdrawn for OGTT during screening for GDM was used for this study. In this study serum glucose was determined by Enzymatic method with GOD-PAP serum and magnesium was determined by colorimetric method using the test kit. The results were analysed statistically and values were expressed as mean \pm SD. The level of significance was determined by employing Student's t test. Only when the $\mathrm{p}$ value was less than 0.05 ; the difference between two groups and subgroups were considered as statistically significant.

\section{Result}

The analytical study showed that magnesium was decline in cases when they are compared with control group. It was observed that mean $\mathrm{Mg}$ was $1.162 \pm 0.307(\mathrm{mg} / \mathrm{dl})$ for cases and $1.666 \pm 0.304$ $(\mathrm{mg} / \mathrm{dl})$ for controls. Statistical analysis of $\mathrm{Mg}$ found that the difference highly significant $(\mathrm{p}<$ 0.001 ). In this study mean maternal age and BMI for case subjects were $28.6 \pm 3.23$ and $26.4 \pm 1.49$ respectively and for control subjects $27.3 \pm 3.13$ and $26.3 \pm 1.27$ respectively. The results were found not significant $(p>0.05)$. In this study patients had family history of diabetes mellitus 58 in 86 GDM patients. The present study showed that serum $\mathrm{Mg}$ level was highly significantly decreased in the GDM women in second trimester as Gr-Ia group compared to healthy controls in the second trimester Gr-IIa group and even when compared GDM women in third trimester $\mathrm{Gr}-\mathrm{Ib}$ and healthy controls in the third trimester Gr-IIb group. 
Table 1: Clinical and Biochemical Characteristics of the study subjects

\begin{tabular}{lccc}
\hline Variables & $\begin{array}{c}\text { Mean } \pm \text { SD } \\
\text { (cases) }\end{array}$ & $\begin{array}{c}\text { Mean } \pm \text { SD } \\
\text { (controls) }\end{array}$ & P value \\
\hline Age & $28.6 \pm 3.23$ & $27.3 \pm 3.13$ & $<0.778$ \\
BMI & $26.4 \pm 1.49$ & $26.3 \pm 1.27$ & $<0.774$ \\
Magnesium $(\mathrm{mg} / \mathrm{dl})$ & $1.162 \pm 0.307$ & $1.666 \pm 0.304$ & $<0.001$ \\
\hline
\end{tabular}

Table 2: Mean serum Magnesium levels comparing between different subgroups $(n=43)$

\begin{tabular}{|c|c|c|c|c|}
\hline Variables & Group & Trimester & $\operatorname{Mean} \pm \operatorname{SD}(\mathrm{mg} / \mathrm{dl})$ & $P$ value \\
\hline GDM & Case (Gr-Ia) & $\begin{array}{c}\text { Second } \\
\text { trimester }\end{array}$ & $1.3884 \pm 0.255$ & \multirow{2}{*}{0.001} \\
\hline $\begin{array}{l}\text { Normal } \\
\text { pregnancy }\end{array}$ & Control (Gr-IIa) & $\begin{array}{l}\text { Second } \\
\text { trimester }\end{array}$ & $1.6651 \pm 0.304$ & \\
\hline GDM & Case (Gr-Ib) & $\begin{array}{l}\text { Third } \\
\text { trimester }\end{array}$ & $0.9349 \pm 0.145$ & \multirow{2}{*}{0.001} \\
\hline $\begin{array}{l}\text { Normal } \\
\text { pregnancy }\end{array}$ & Control (Gr-IIb) & $\begin{array}{l}\text { Third } \\
\text { trimester }\end{array}$ & $1.6674 \pm 0.308$ & \\
\hline
\end{tabular}

Student's - t test was used to analyses the data between groups

\section{Discussion}

In this study, we estimated serum magnesium levels in GDM subjects (case) and healthy pregnant women (controls). Serum magnesium concentration of the GDM patients was highly significantly $(\mathrm{P}<0.001)$ lower when compared with that of control. Our study findings is supported by the studies of Bardicef et al. (1995)13, Takaya et al. $(2006)^{14}$ Yinsong Wang et al. ${ }^{15}$ (2002). They explained that the decrease in serum magnesium might be due to magnesium depletion caused by osmotic diuresis and by indirect hormonal effects. The low serum magnesium levels seen in the diabetic population may be a consequence of insulin resistance and dietary magnesium intake and intestinal hypo absorption may also be a factor in the low serum magnesium levels. Goker Tasdemir et al. $(2015)^{16}$ found that there is no statistically significant difference in serum magnesium concentrations between healthy pregnant women and women with GDM.

\section{Conclusion}

Analysing the finding of the present study, significant alteration in Serum magnesium level was observed in GDM Patients. Therefore it might be recommended that estimation of this biochemical parameter in GDM patients should be carried out for earlier detection and management the complications of GDM.

Conflict of interest: We have no conflict of interest.

\section{References}

1. WHO. Definition, Diagnosis and Classification of Diabetes Mellitus and its Complications. Report of a WHO consultation. Part 1: Diagnosis and Classification of Diabetes Mellitus Geneva: Department of Non communicable Disease Surveillance, World Health Organization, 1999.

2. Buckley, B. S., Harreiter, J., Damm P., et al. and on behalf of the DALI Core Investigator Group. 2012. Gestational diabetes mellitus in Europe: prevalence, current screening practice and barrier to screening. A review. Diabet. Med. 2012; 844-854

3. Gokcel, A., Bagis, T., Killicadag, E. B., et al. 2002. Comparison of the criteria for gestational diabetes mellitus by NDDG and Carpenter and Coustan, and the outcomes of pregnancy. $J$ Endocrinol Invest 2002; 25: 357-61.

4. Alam, M. R. 2006. Gross and Histomorphologic study of Umbilical cord in pre-gestational diabetes mellitus (thesis). BSMMU; Bangladesh.

5. Reece, E.A.,Wu,Y. K. Wiznitzer. A. role of free radical in membrane lipid induced congenitalmalformation. J Soc Gynaecol Invest 1998; 5(9): 178-187.

6. Ajose, A., Fasubaa, B., Anetor, J. I., et al. Serum zinc and copper concentrations in Nigerian women with normal pregnancy. Niger Postgrad Med, J 2001; 8: 161-164. 
7. Ladipo OA. Nutrition in pregnancy: mineral and vitamin supplements. American Journal of clinical Nutrition 2000; 72: 280-290.

8. Saris NE, Mervaala E, Karppanen $\mathrm{H}$, et al. Magnesium: an update on physiological, clinical, and analytical aspects. 2000. Clinica Chimica Acta, 294: 1-26.

9. Shaikh MK, BR, Devrajani AA, Soomro, S.Z.A. Shah, et al. World Applied Sciences Journal 2011; 12(10): 1803-06.

10. Cook, L. A. and Mimouni, F. B. Whole blood ionized magnesium in the healthy neonate. 1997. J. Am. Coll. Nutr, 1: 181-3.

11. Ertbeg P., Norgaard P., Bang L., et al. Ionized magnesium in gestational diabetes. Magnes Res 2004; 17(1): 35-8.

12. Takaya, J., Yamato, F. and Kanelco, K. Possible relationship between low birth weight and magnesium status: from the standpoint of foetal originhypothesis. Magnes. Res 2006; 19: 630-9.
13. Bardicef, M., Bardicef, O., Sorokin, Y., et al. Extracelluar and intracellular magnesium depletion in pregnancy and gestational diabetes. American Journal of Obstetrics and Gynecology 1995; 172: 1009.

14. Takaya, J., Yamato, F. and Kanelco, K. Possible relationship between low birth weight and magnesium status: from the standpoint of "foetal origin" hypothesis. Magnes. Res 2006; 19: 630-9.

15. Wang Y, Tan M, Huang Z, et al. Elemental contents in serum of pregnant women with gestational diabetes mellitus. Biol Trace Elem Res 2002; 88(2): 113-118.

16. Goker Tasdemir U, Tasdemir N, Kilic S, et al. Alterations of Ionized and Total Magnesium levels in Pregnant Women with Gestational Diabetes Mellitus. 2015. Gynecol Obstet Invest. 79: 19-24.

17. Bardicef M, Bardicef $\mathrm{O}$, Sorokin $\mathrm{Y}$, et al. Extracellular and intracellular magnesium depletion in pregnancy and gestational diabetes. American Journal of Obstetrics and Gynecology 1995; 172: 1009. 